\title{
Por uma Compreensão Poética da Memória (Adélia Prado e Astrid Cabral)
}

Angélica Soares (UFRJ)

\begin{abstract}
RESUMO: Reflexões sobre a memória e o discurso literário memorialístico em diálogo com poemas selecionados de Adélia Prado e Astrid Cabral que, se constituindo como metamemória, desvelam a natureza ilimitável da memória; tornando improcedente fragmentar o tempo em momentos estanques; demarcar fronteiras entre percepção e imaginação, realidade e ficção; limitar o sujeito da recordação a uma concepção fechada. Imagens adelianas de $O$ coração disparado remetem para a indestrutibilidade do que se constrói pela memória e para o seu sentido simbólico e comemorativo. Em Lição de Alice, Cabral recria humanos pré-sentimentos apontando para a mobilidade temporal, o caráter inventivo e a ação geradora da memória. Nessas obras, surpreendem-se proustianos signos sensíveis da memória, edificantes do re-cordar.
\end{abstract}

PALAVRAS-CHAVE: Adélia Prado; Astrid Cabral; memória

ABSTRACT: Reflections on the memory and the reminescent literary speech in dialogue with selected poems of Adélia Prado and Astrid Cabral that, built as metamemory, reveal the unlimited nature of memory; it is improper to break up the time in stanched moments, to demarcate borders between perception and imagination, reality and fiction, to limit the subject of the memory to a closed conception. Adelian images of the $O$ coração disparado send for the indestructibility of that if it constructs for the memory and for its symbolic and commemorative direction. In Lição de Alice, Cabral recreates human pre-feelings pointing with respect to secular mobility, the inventive character and the generating action of the memory. In these books, one may be surprised by proustian sensible signs of the memory, edifying remembrances.

KEYWORDS: Adélia Prado; Astrid Cabral; memory

Ao voltar-me para a compreensão da memória e do memorialismo literário, definições e conceitos me pareceram insuficientes; daí ter optado por buscar diálogos possíveis com textos poéticos selecionados, que me permitissem introduzir a permanente tensão entre lembrar e esquecer, pensada, aqui, como um dos pilares do nosso dinamismo existencial.

Neste trabalho, detenho-me na leitura de poemas de $O$ coração disparado, de Adélia Prado e Lição de Alice, de Astrid Cabral, nos quais pude detectar a configuração de uma metamemória, uma vez que neles, a memória poematizada conduz à uma 
reflexão sobre a sua própria dinâmica. Assim, ela faz-se objeto do poema, deixando-nos vestígios de seu mostrar-se e retrair-se, promotores da historicidade humana: de tudo o que o ser humano é e faz, em sua temporalidade unitária, tridimensional, simultaneamente presente, passado e futuro (SOARES, 2004, p. 300-1).

Em $O$ coração disparado, Adélia Prado ressalta, superlativamente, a natureza afetiva e mágica da memória quando se refere, no poema intitulado "A casa", a uma “casa de esquina”, não localizável geograficamente, como habitação reconstruída memorialisticamente:

É um chalé com alpendre, forrado de hera.

Na sala, tem uma gravura de Natal com neve.

Não tem lugar pra esta casa em ruas que se conhecem.

Mas afirmo que tem janelas,

claridade de lâmpada atravessando o vidro, um noivo que ronda a casa

- esta que parece sombria -

e uma noiva lá dentro que sou eu.

É uma casa de esquina, indestrutível.

Moro nela quando lembro,

quando quero acendo o fogo,

as torneiras jorram,

eu fico esperando o noivo, na minha casa aquecida.

Não fica em bairro esta casa

infensa à demolição.

Fica num modo tristonho de certos entardeceres, quando o que um corpo deseja é outro corpo pra escavar. Uma idéia de exílio e túnel. (PRADO 1987: 24)

A memória habita, liricamente, o poema adeliano e, como lhe é próprio, "sensível a todas as transferências (...) se enraíza no concreto, no espaço, no gesto, na imagem, no objeto" (NORA 1993: 9); daí, a fruição de cada detalhe, que conduz ao mergulho do sujeito nos seus mais sinceros desejos. Assim, nos é possível visualizar cenas e projeções do interior para o exterior e vive-versa, no movimento de imersão das coisas no sujeito e de emersão do que lhe vai de mais íntimo: movimentos que acabam por se inter-relacionar, “... num modo tristonho de certos entardeceres". Esses motivadores involuntários da memória, mobilizam a busca erótica de "continuidade do ser" (BATAILLE 1980: 17; 91-2), que ocorreria pela penetração de um corpo em outro 
corpo. E lembremos, mais uma vez, com Pierre Nora, que a verdadeira memória se abriga também "nos saberes do corpo" (NORA 1993: 14).

Em Adélia Prado, a casa é a casa, onde não há limites para a fantasia e para o desconhecido e é, ainda, o lugar do "exílio", que se quer compartilhado, pois "o que um corpo deseja é outro corpo pra escavar". E o que se espera escavar no outro é uma travessia, uma passagem, um "túnel” para a vida. Essa casa existe e é "indestrutível", porque construção de memória ("infensa à demolição").

No universo adeliano, em "ruas que se desconhecem", situa-se a morada da memória, uma vez que ela penetra o inconsciente, com suas dimensões incapturáveis a nos deixarem a sensação da falta e das lacunas intraduzíveis pela palavra. E porque a memória resguarda o silêncio, o que se edifica por ela não se esgota e não se destrói. Possuidora de uma força incalculável, sustenta uma permanência que não se deixa controlar; como diria Nora, "susceptível de longas latências e de repentinas revitalizações" (NORA 1993: 9). A "casa aquecida" de Adélia Prado nos oferece uma experiência instigantemente poética, iluminada pelo vigor revitalizante da memória, com a simbólica "claridade de lâmpada atravessando o vidro", desnudando transparências insuspeitadas.

Adélia Prado parece-nos querer lembrar, com as lições heideggerianas, que "poeticamente o homem habita" (HEIDEGGER 2002: 165-81) quando vivencia a essência do habitar (HEIDEGGER 2002: 127), construindo-se e questionando-se em sua humanidade.

A consciência adeliana da memória, como um modo fugidio de experienciação, que é inalienável da existência humana, se explicita também em $O$ coração disparado, no poema, cujo título "Subjeto" nos parece preservar a idéia do que se lança de baixo, dos recônditos territórios do inconsciente para a consciência: em associações espáciotemporais de objetos, lugares, sensações etc. que o recordador parece querer conservar tais quais foram vividas e / ou imaginadas e, ao mesmo tempo, quer transmiti-las com palavras, embora saiba que estas as deformam, por conformá-las sempre diferentemente: 
O cheiro da flor de abóbora, a massa de seu pólen, para mim, como óvulo de coelhas.

- Vinde zangões, machos tolos,

picar a fina parede que mal segura a vida, tanto ela quer viver.

Ainda que não vos houvesse

eu fecundaria essas flores com meu nariz proletário.

- Ora, direis, um lírio ignóbil.

Pois vos digo que a reproduzo em ouro

sobre meu vestido de núpcias, meu vestido de noite.

Dentro do quarto escuro,

ou na rua sem lâmpadas, de cidade ou memória,

um sol.

Como pequenas luzes esplêndidas. (PRADO 1987: 27)

Em "Subjeto", como em toda a escrita poematizada da memória, o verso, cortando as frases, expõe os cortes entre o vivido ou o possivelmente vivido e o narrado, de forma predominantemente lírica, abrindo-se sulcos transversais para a passagem do imaginário e, com ele, o trânsito para o sentido simbólico das imagens relembradas que, acionadas pela imaginação, reúnem, muitas vezes, o que nos poderia parecer sem nenhuma relação aparente, não fosse o significado emocional e existencial que têm elas para o recordador.

E como não atentar para a impossibilidade de se criarem fronteiras entre memória e imaginação? Cabe-nos reconhecer, conforme sintetizou Eduardo Portella, o caráter inventivo da memória: “C'est une invention d'ont la memoire nous fournit elle même la matière première." (2003: 3). A força da memória está, mesmo, em sua inclinação para metamorfosear-se e recriar-se. Manuel de Barros, em seu poema "As lições de R. Q.", integra memória e criação ao reconhecer a humana necessidade de "transver o mundo". Em verso antológico, ele registra o ato de transvisão, que diz melhor dessa natureza imaginativa da memória: "O olho vê, a lembrança revê, e a imaginação transvê" (BARROS 1997: 75); uma vez que o que ficou para trás, se torna irresgatável em sua realidade palpável, assim como o que, na memória, já se projeta para o futuro. Transver é, pois, a própria experiência do acontecer memorante.

$\mathrm{Na}$ imaginação, incidem o alargamento do pensar, o risco da irrealidade, a previsão e até a vigília para a possibilidade de algo relacionado aos acontecimentos presentes e passados. Relaciona-se, assim, comumente à idéia do inexistente. Por outro lado, é a capacidade para criar algo que, ganhando forma, se torna possível, pois há uma 
força prospectiva na imaginação, pela qual temos acesso a uma presentificação do ausente, a partir do percebido. Perceber e imaginar são atos simultâneos e se impregnam mutuamente embora, comumente, tentemos diferençá-los. O que Adélia Prado parece nos dizer é tudo isso e não só. É que na ação de lembrar contamos com a imaginação, pois que os fatos não se revivem, reconstroem-se, recriam-se nos descontínuos e lacunares movimentos temporais da rememoração. E assim é porque há "necessidade de basear a vida complexa numa pluralidade de durações que não têm nem o mesmo ritmo, nem a mesma solidez de encadeamento, nem o mesmo poder de continuidade" (BACHELARD 1988: 7) atendendo à diversidade dos fenômenos temporais, percebida na tarefa de seriar os seus diferentes planos. A linearidade de um tempo único para todos os fenômenos, os resume sempre de forma imperfeita.

Desse modo, a recordação do que estaria subjacente na memória caminha, direcionada pelas forças geradoras das sensações, da "flor de abóbora" com o seu "pólen" para a "fecundação", as "núpcias", o "quarto escuro" ou a "rua sem lâmpadas", que se iluminam pelo "ouro" da "flor de abóbora", já agora bordada no "vestido de noite", a resplandecer como um sol, conjugando todas as "pequenas luzes esplêndidas" e aí o valor esplendoroso do que poderia aparecer como um "lírio ignóbil" é o que se preserva. E, se essa "rua" é "de cidade ou de memória" não importa. O que importa para a recordadora é a natureza solar do seu desejo simples e "proletário" de viver e de produzir vida.

Em sua dimensão metamemorialística, o poema explicita, ainda, a postura adeliana de dramatização da memória, que dinamiza a interação, desde sempre existente no memorialismo poético, entre narração e lirismo. Em "Subjeto", o lírico se associa ao narrativo e ao dramático e, assim, todas as dimensões do humano se juntam para trazer à tona fragmentos que permitem reconstituir a vida fragmentada pela cronologia.

Os discursos diretos ou indiretos do sujeito, a associarem fala e gesto, impõem a forma do monólogo, que intensifica a convicção, transmitida pela recordadora, da densidade dos pequenos-grandes momentos de "luzes esplêndidas"; como também são aqueles rememorados em "Solar": "Minha mãe cozinhava exatamente: / arroz, feijão roxinho, molho de batatinhas. / Mas cantava" (PRADO 1987: 28). 
Esses são momentos epifânicos, ensolarados, que Adélia Prado conserva no exercício poético de epifania da linguagem, quando se atinge o máximo de sentido, no mínimo de palavras, deixando-se irradiar a natureza "solar" iluminadora e fecundante do silêncio, pelas entrelinhas do poema e pelas entrelinhas da memória.

Se, em "Subjeto", a poetisa de Divinópolis ressalta, de início, o poder evocativo do olfato, em "O guarda-chuva preto", o olhar se encarrega de mobilizar memória e metamemória, na construção dos versos:

Esquecido na mesa,

com o cabo voltado para cima

e as bordas arrepanhadas,

é como seu dono vestido,

composto no seu caixão.

Não desdobra a dobradiça,

não pousa no braço grave

do que, sendo seu patrão,

foi pra debaixo da terra.

Ele, vai para o porão.

Existe um retrato antigo

em que pousou aberto,

com o senhor moço e sem óculos.

Guarda-chuva, guarda-sol,

guarda-memória pungente

de tudo que foi em nós

um pouco ridículo e inocente.

Guarda-vida, arquivo preto,

cão de luto, cão jazente. (PRADO 1987: 22)

O símile do quarto verso introduz o pensar dinâmico e simultâneo na vida e na morte, porque simultâneos são seus modos de ser. A partir do mesmo verso, pela agilidade nas associações, que caracteriza o estilo adeliano, ligam-se sujeito e objeto, num processo de analogias, encadeamentos e gradações que culminam na metamorfose de um simples "guarda-chuva preto" em um "guarda-memória pungente" e, pela pungência da memória, um "guarda-vida". E, como "guarda-memória", o sujeito recordador se pluraliza e nos inclui a todos em nossa finitude. Aquele "guarda-chuva preto" passa a simbolizar, então, o "arquivo preto" de todos nós, como a querer a poetisa nos remeter para a "consciência comemorativa da memória" (NORA 1993: 12) que detém, no prefixo "com", a sua ação como um resgate sempre comunitário, mesmo quando recomposto individualizadamente. 
Nos desdobramentos finais da "imagem-lembrança": "guarda-chuva", "guardasol", "guarda-memória", "guarda-vida" parece-me delinear-se a atuação da memória como revelação repentina de um passado (aí gravado em "um retrato antigo") que busca presentificar-se no discurso.

$\mathrm{Na}$ forma do presente do indicativo do verbo "existir" fica textualizado o presente presentificante, a permitir que o presentificado (“o senhor moço e sem óculos") chegue até nós e nos ponha em guarda ("cão de luto, cão jazente") para a nossa transitoriedade.

Astrid Cabral, por sua vez, traz-nos o sentido da pré-visão indicado na referência ao "amanhã", remetendo-nos para a atuação geradora da memória, a promover em nós a ocorrência da antecipação. E essa antecipação revela, em últimas instâncias, o nosso modo de ser no mundo, que é o de ser-no-mundo-para a morte; o que Heidegger assim fundamentou, ontologicamente:

O "ser-aî" tem noção do tempo fugitivo porque a deduz do "fugitivo" saber de sua morte. No falar com maior ênfase do passar do tempo há um reflexo explícito do advir finito da temporalidade do "ser-aí". E por poder permanecer a morte encoberta até no falar do passar do tempo, se mostra o tempo como um passar "em si". (HEIDEGGER 1977: 458-9)

A literatura memorialística (e, por isso, inventiva) leva-nos a concluir, pelas mãos de Proust que, ao redescobrir-se o tempo, o que temos não é a representação literária do tempo vivido, mas o revelar (enquanto velar-se no desvelado) da essência temporal da realidade, que irrompe das ruínas, no impalpável do presente e no mais além do futuro, que a literatura garante em seus deslimites:

Mas quando mais nada subsistisse de um passado remoto, após a morte das criaturas e a destruição das coisas, sozinhos, mais frágeis porém mais vivos, mais imateriais, mais persistentes, mais fiéis, - o odor e o sabor permanecem ainda por muito tempo, como almas, lembrando, aguardando, esperando, sobre as ruínas de tudo o mais, e suportando sem ceder, em sua gotícula impalpável, o edifício da recordação. (PROUST 1983: 47) 
Esses proustianos signos sensíveis da memória, edificantes do re-cordar (do pôr de novo no coração) comparecem na produção literária de Astrid Cabral pela ambigüidade sensorial, na qual se alicerçam as tensões do tempo em Lição de Alice. Aí, o pré-ser-se da memória figuriza-se como "Véspera", antecedendo-se à "própria história":

Sem saber de que chafariz jorrariam as lágrimas nem de que ferida braba nasceria a cicatriz à véspera da própria história aspirávamos o amanhã flor de maçã, white magnólia. (CABRAL 1986: 88)

No modo astridiano de recriação lírica da mobilidade temporal da memória, o futuro do pretérito melhor diz da vigília do sujeito à espreita das dores inevitáveis e de suas marcas, cicatrizadas pela ação do tempo após a pré-sentida "ferida braba". Sendo assim, recorda-se um amanhã desejado e já fruído nas fragrâncias da "flor de maçã" e da "white magnólia", essências de perfumaria que testemunham o poder evocativo dos signos olfativos que se impregnam na alma e, como almas em sua imortalidade, espreitam-nos, à espera de manifestar-se. Ensinando a suportar a dor do crescimento e da finitude, a memória brinda o ser com a evasão criativa, libertadora, que nos faz esquecer, "cicatrizar" as danificações e até brincar, divertir-nos, inventar a vida, também na invenção da linguagem.

É pelo viés desse divertimento, que Astrid Cabral joga explicitamente, com as sugestões semânticas da língua e que, infantilmente (como Alice, de Carroll) prefere pensar, recriar o pensamento que pensa os mistérios do futuro, ainda não atravessados: envoltos no presente. Assim, ela une todos os tempos, em "Vesperal".

Enxerto-me no ontem:

eis-me à janela de gerânios

num recanto de Londres.

Um sol de sangue parafraseia-me

o coração sangria desatada.

Ainda não atravessei

o mistério do meu futuro.

(A vida, um presente no embrulho). (CABRAL 1986: 89) 
A partir do título, instala-se a ambivalência dos signos. "Vesperal" liga-se à véspera, à tarde, à idéia de tudo o que precede um acontecimento e até à festa, a divertimento. O presente é véspera do futuro, mas também o que se ganha como regalo, com intento de agradar, de alegrar, de divertir. "Sangria desatada", como grande perda de sangue, é o que precisa de atendimento imediato: os apelos do "coração". Na inversão maneirista, o que se exprime externamente (a cor sangüínea do sol) reflete o sentimento do eu ("parafraseia-me"); o que traz ao poema, além do emblematismo natural, a consciência de que se trata de um jogo lingüístico, de um divertimento com as potencialidades da língua, na criação de novos modos de dizer. Por isso, também, por identificação com os "gerânios", o eu enxerta-se na véspera do hoje para conviver com o amanhã, ainda não desvelado.

Não se trata, portanto, apenas de reconstruir-se o passado no presente da recordação, mas de reconhecer que a memória instala uma incessante tensão com o futuro. Esta nos aparece como uma das lições da reflexividade memorialística do poema e via de acesso a uma compreensão mais abrangente da relação entre tempo e memória.

Adélia Prado e Astrid Cabral, relembradas nesta comunicação, parecem querer revelar, nas entrelinhas do texto, que também no discurso a vida se constrói e o sujeito articula, privilegiadamente, a experienciação temporal, sempre alicerçada nos ilimitáveis da memória.

\section{OBRAS CITADAS}

BACHELARD, Gaston. 1988. A dialética da duração. Trad. Marcelo Coelho. São Paulo: Ática.

BARROS, Manoel de. 1997. Livro sobre nada. 3. ed. Rio de Janeiro: Record.

BATAILlE, Georges. 1980. O erotismo. 2. ed. Trad. João Bénard da Costa. Lisboa: Moraes.

CABRAL, Astrid. 1986. Lição de Alice. Rio de Janeiro: Philobiblion.

HEIDEGGER, Martin. 1977. El ser y el tiempo. Trad. José Gaos. México: Fondo de Cultura Económica.

2002. Construir, Habitar, pensar. In: _.. Ensaios e conferências. 2. ed. Trad.

Emmanuel Carneiro Leão et aliii. Petrópolis: Vozes. 125-41. 
2002. ... poeticamente o homem habita. In: _. Ensaios e conferências. 2. ed. Trad. Emmanuel Carneiro Leão et aliii. Petrópolis: Vozes. 165-81.

NORA, Pierre. 1993. Entre memória e história: a problemática dos lugares. Trad. Yara Aun Khoury.Projeto história (São Paulo) 10: 7-28.

PORTELLA, Eduardo. 2003. Paradoxes de la mémoire. Diogéne (Paris) 201: 3-4.

PROUST, Marcel. 1983. No caminho de Swann. Trad. Mário Quintana. 8. ed. Porto Alegre: Globo.

PRADO, Adélia.1987. O coração disparado. 4.ed. Rio de Janeiro: Guanabara.

SOARES, Angélica. 2004. O apelo poético-memorialístico do ilimitado em Mulher no palco, de Lya Luft. In: CASTRO, Manuel Antônio de; Org. A construção poética do real. Rio de Janeiro: 7 Letras. 298-310. 